\title{
Experimental and Numerical Analysis of Fatigue during the Cyclic Loading
}

\author{
Petra Kováčiková*, Jan Vavro, Jan Vavro. jr. \\ University of Alexander Dubček in Trenčín, Faculty of Industrial Technologies, I. Krasku 491/30, 02001 Púchov, Slovakia \\ *Corresponding author: pepekovacikova@gmail.com
}

Received October 10, 2014; Revised October 30, 2014; Accepted November 14, 2014

\begin{abstract}
The presented paper is devoted to the whole complex of problems relating to the experiments of the mechanical fatigue for the determination of the materials parameters and characteristics of the structural properties. The experimental determination of Wöhler fatigue curve and knowledge in relation to the material data for the tested construction material is based on the experimental results of the testing machine SCHANCK used for determination of the mechanical fatigue. In the given work, there is the introduction of the research in the field of the fatigue based on cyclic loading by bending and moreover, the given research is combined with the modern computational methods of the mechanics of continuum. In relation to the numerical analysis, the given thesis is focused on the creation of the computational model according to the geometry of the tested sample in an experimental way and this computational model can help us to obtain the most reliable results for the simulation of the loading with utilisation of the computational program system on the basis of the finite element method. The total numerical time was also taken into account because of the achievement of the fast response to the change of the material, geometrical and other parameters during the creation of the computational model. The obtained results based on the experimental analysis as well as numerical analysis were mutually compared. The numerical analysis and experimental measurement can be also applied for the other types of materials.
\end{abstract}

Keywords: fatigue, cyclic loading, finite element method, steel

Cite This Article: Petra Kováčiková, Jan Vavro, and Jan Vavro. jr, "Experimental and Numerical Analysis of Fatigue during the Cyclic Loading." American Journal of Mechanical Engineering, vol. 2, no. 7 (2014): 295-298. doi: 10.12691/ajme-2-7-26.

\section{Introduction}

The research in the area relating to fatigue lifetime is closely connected with the comparison of the experimental methods with the numerical analysis. The given paper is focused on the various problems involving experiments of mechanical fatigue which is based on the system of predetermined frequency of cycling loading where the vibration stress is performed during the rotation movement of the tested sample which is loaded by bending. The determination of Wöhler curve as well as acquisition and completion of all material as well as geometric data on construction material can be considered as the basic or initial material data for specification of the in-put parametres leading to creation of the numerical analysis. The given numerical analysis can allow us to make simulation of the loading process using the computer program system which is based on the finite element method (FEM). The computer program system ADINA was used for the numerical analysis mentioned hereinbefore. The mutual comparison of the results obtained by help of experimental investigation and numerical method can lead to formation of the new results and new points of view in relation to solution of the problems in this scientific area and moreover, it can be useful for further research and development of new approaches referring to the mechanical fatigue as well as initiation and propagation of the fatigue cracks which can occur in the practice when the operating parts are under the cyclic loading [1].

\section{Material Characteristics}

Table 1. Chemical composition of the 17240 steel in wt. \% (designated according to STN)

\begin{tabular}{|c|c|c|c|c|c|}
\hline Material & $\mathrm{C}$ & $\mathrm{Mn}$ & $\mathrm{Si}$ & $\mathrm{P}$ & $\mathrm{S}$ \\
\hline $\mathbf{1 7 2 4 0}$ & 0.065 & 0.58 & 1.05 & 0.024 & 0.011 \\
\hline Material & $\mathrm{Cr}$ & $\mathrm{Ni}$ & $\mathrm{Mo}$ & $\mathrm{Cu}$ & $\mathrm{W}$ \\
\hline $\mathbf{1 7 2 4 0}$ & 19.09 & 7.42 & 0.17 & 0.06 & 0.058 \\
\hline
\end{tabular}

Table 2. Mechanical properties of the 17240 steel (designated according to STN)

\begin{tabular}{|c|c|c|c|c|}
\hline Material & $\mathrm{R}_{\mathrm{P} 0,2}[\mathrm{MP}]$ & $\mathrm{R}_{\mathrm{m}}[\mathrm{MPa}]$ & $\mathrm{A}[\%]$ & $\mathrm{Z}[\%]$ \\
\hline 17240 & 263 & 643 & 65.8 & 76.8 \\
\hline
\end{tabular}

The predetermined tests were performed for the samples with the specified proportions and these samples were prepared from the austenitic chrome-nickel steel with designation: 17240 while the given designation is based on the Slovak Technical Standard (STN). The mechanical properties of the mentioned steel were determined on the basis of the static tensile test. The chemical composition (Table 1) and the values 
representing the mechanical properties (Table 2) of the tested steel are shown in the tables hereinafter [1].

Based on the observations, the microstructure of the tested chrome-nickel steel sample (Figure 1) consists of polyhedric austenitic and quite large grains. It is also important to point out that the mechanism of twining is observed in relation to this steel and the occurrence of delta-ferrite particles can be seen in surface layers [1].

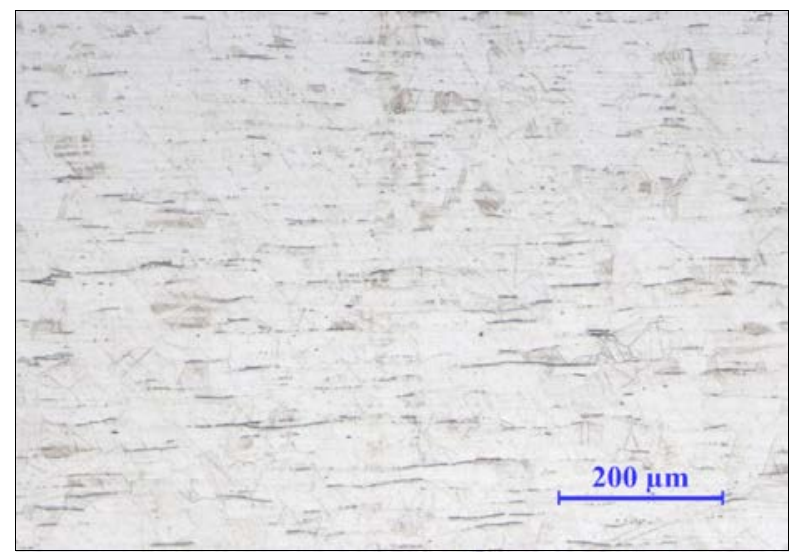

Figure 1. The microstructure of the 17240 steel [1]

\subsection{Fatigue Test Based on Bending Cycles During the Rotation Movement}

The testing procedures were performed for samples with round cross-section and determined radius. It has to be pointed out that the fatigue limit is susceptible to the surface quality and it means that it is reduced if there is the oxidation process on the material surface or if there is any surface roughness after the machining process where the material removal is accompanied with the occurrence of chips. According to the fact mentioned hereinbefore, the polishing procedure was used for the final surface treatment and this given procedure was performed in the direction which was parallel to the longitudinal axis of the rod used for preparation of the samples. The given procedure led to the smooth and polished surface [2].

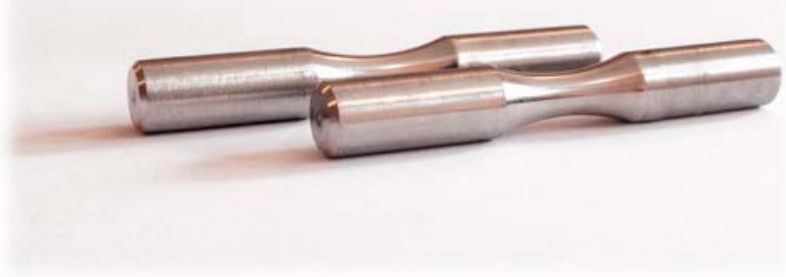

Figure 2. The shape of the tested sample

The testing device SCHNECK was used for performance of the fatigue tests. The given testing process was based on the predetermination of the initial stress $\left(\sigma_{1}\right)$ for the first one tested rod or sample and the given predetermined initial stress was less than $R_{e}$ standing for the highest admitted yielding stress for the tested material. In relation to the other tested samples, the gradual decreasing of the stress led to recognition of the values representing the specified number of cycles $(\mathrm{N})$ referring to the condition when the sample was able to withstand the specified number of cycles. After the breakage of the first one tested sample, the gradation scale of the stresses was determined for the each one sample while the loading frequency was still the same. The testing procedure was performed until the critical values of the stress were found out. The mentioned critical values were used for determination of the fatigue limit and they represent the stress at which the sample is able to withstand the number of cycles until it is broken. In the case of one sample, the control testing was carried out to confirm the results. In relation to the given control testing procedure, the loading of sample was less by $10 \mathrm{MPa}$. All of testing procedures were performed continuously and besides fracture, the visible crack was considered as the end of the mentioned testing process (Figure 3) [3].

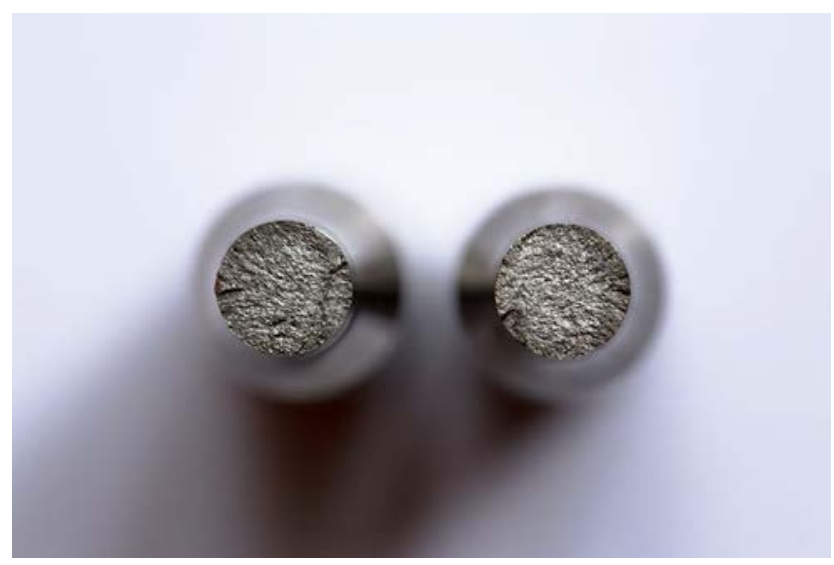

Figure 3. Sample of the 17240 steel after the testing procedure fracture [1]

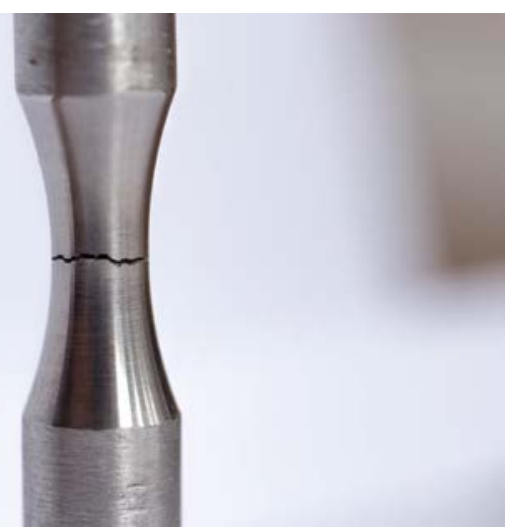

Figure 4. Sample of the 17240 steel after the testing procedure fracture

\subsubsection{The Results of Measurement and Numerical Analysis}

In relation to the tested rods or samples of the 17240 chrome-nickel steel, the predetermined initial stress, stress based on gradation scale and results of experimental testing process are shown in Table 3.

\begin{tabular}{|c|c|c|c|c|}
\hline 17240 & 1 & 2 & 3 & 4 \\
\hline$\sigma[\mathrm{MPa}]$ & 250 & 240 & 230 & 220 \\
\hline $\mathrm{N}$ & 13000 & 15300 & 32700 & 45900 \\
\hline 17240 & 5 & 6 & 7 & 8 \\
\hline$\sigma[\mathrm{MPa}]$ & 210 & 200 & 190 & 180 \\
\hline $\mathrm{N}$ & 102900 & 270200 & 10468200 & 10102800 \\
\hline
\end{tabular}

Based on $\sigma-\log N$ logarithmic system, Wöhler fatigue curve was evaluated on the basis of the obtained results referring to the condition when the tested sample under the specific stress $(\sigma)$ was able to withstand specific 
number of cycles (N). The resulting course was approximated by slanting and linear line [4].

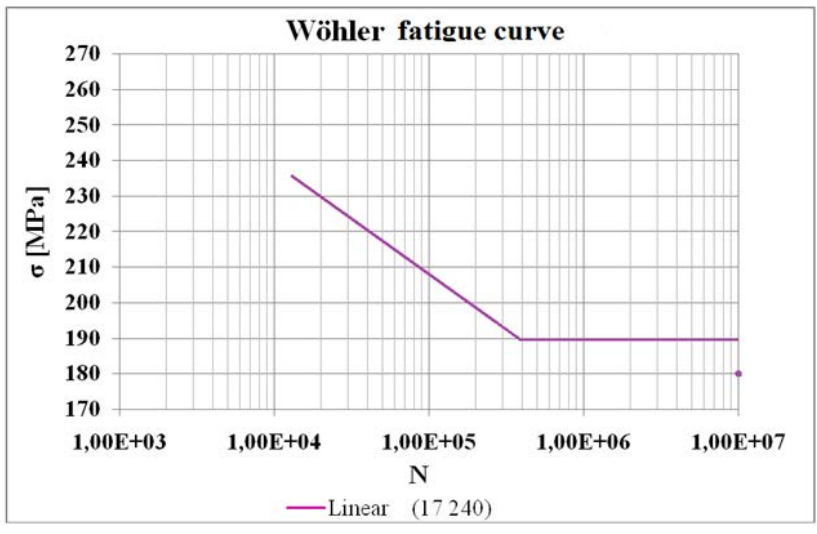

Figure 5. Wöhler fatigue curve - experimental analysis

\subsection{Numerical Analysis}

The basic model of the sample was created in the ADINA program (Figure 6). The linear-elastic model was selected for the analysis while the given model was based on the fact that there was the rotation movement of the loading force in the points at the ends of the model around the circumference of the sample with reference to time intervals. The material characteristics, critical conditions were defined and subsequently, the mesh was created. The highest stress concentration was expected in the area where the sample was the thinnest and therefore, the smaller size of element was selected because of higher density of mesh and accuracy of the solution [5].

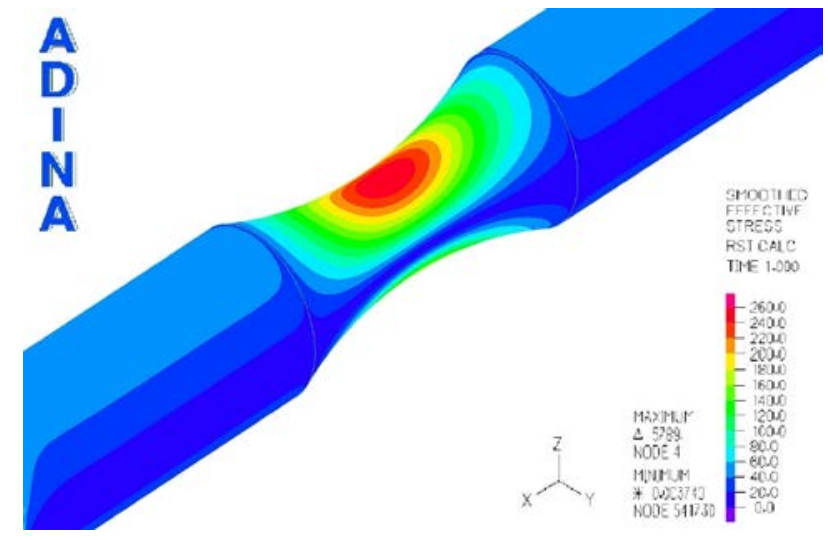

Figure 6. Numerical analysis [3]

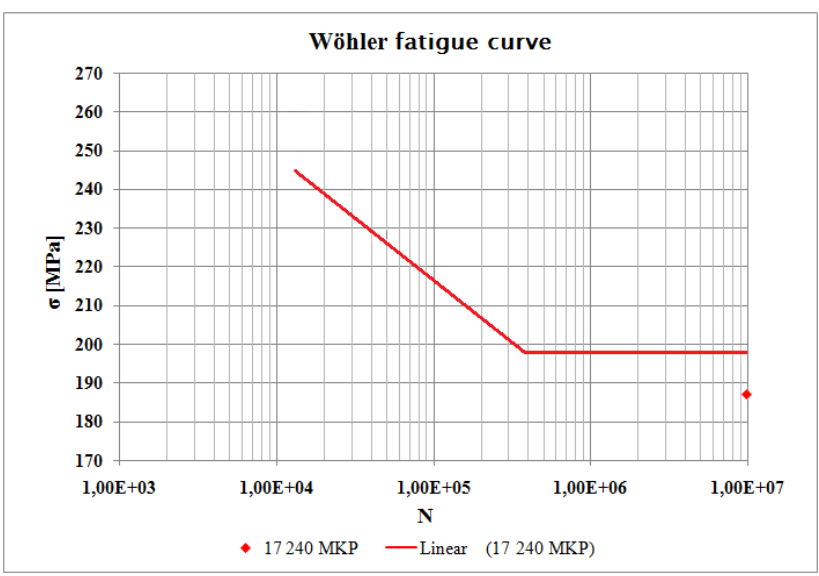

Figure 7. Wöhler fatigue curve - numerical analysis

\subsubsection{Results of Measurements - Numerical Analysis}

The values representing stresses $(\sigma)$ and individual bending moments (Figure 7) were obtained from the numerical analysis of the model based on finite element method.

\section{Discussion}

The value standing for $\sigma$ is the critical loading in relation to the fatigue limit $\left(\sigma_{\mathrm{C}}\right)$. The mentioned critical loading means that the sample was able to withstand the basic number of the cycles $(\mathrm{N})$ without any rupture when the middle stress $\left(\sigma_{\mathrm{m}}\right)$ was used. During the testing procedure, the value of the stress was changed gradually in relation to the individual samples and it corresponds to the alternating regular cycle. It is important to point out that the value representing unbroken sample loaded by the basic number of cycles $(\mathrm{N})$ is equal to the fatigue limit when the $\sigma_{\mathrm{m}}=0$ [4].

In relation to the 17240 chrome-nickel steel, the results obtained from the experimental and numerical analyses were mutually compared using the trend lines of the Wöhler curve referring to the stress and the number of cycles until the breakage. The results for both methods are shown as the curves in the created graph (Figure 8)

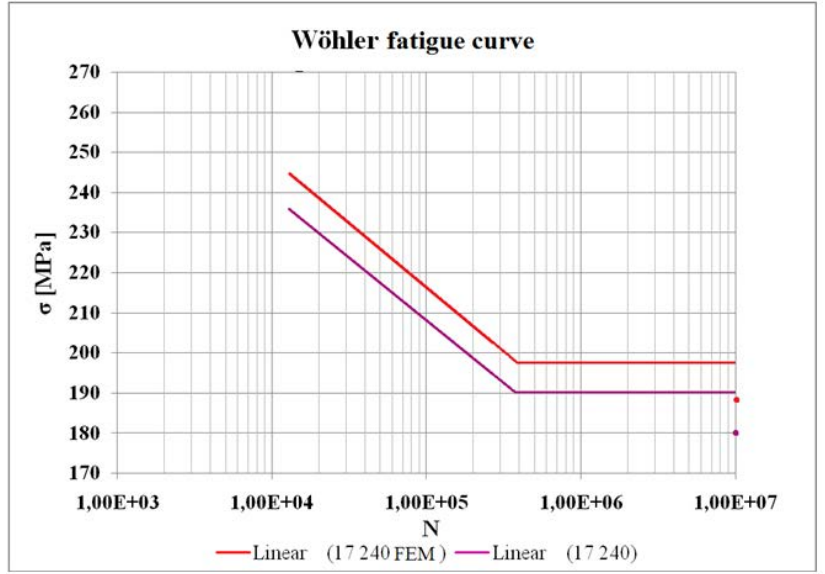

Figure 8. Wöhler fatigue curves for both methods [3]

On the basis of the out-put data, it can be concluded that there is the partial accordance between the experimental results and the numerical results. Differences between the deviations of the values can be attributed to the inaccuracy of the measurement and influence of the internal and external factors regarding to the experimental part while these factors were not defined in the numerical part.

\section{Conclusion}

The given paper is focused on the combination of the experimental and numerical methods which were used for acquisition of the results for fatigue limit using the creation of Wöhler fatigue curves. The experimental part is closely connected with testing of material using fatigue test based on bending cycles during the rotating movement (cyclic loading) and moreover, it also includes the analysis which results from the finite element method. In relation to the mechanical fatigue, the testing procedure was 
performed with help of special measurement device SCHENCK and numerical analysis was carried out with help of ADINA software which was used for the complete analysis from modelling of sample up to final calculation. The obtained results can be contribution in the sphere of the material engineering as well as applied mechanics and they can also bring the new approaches to the solutions of the whole complex of problems.

\section{Acknowledgement}

This work has been supported by VEGA grant No.1/0385/14 and KEGA grant No. 007 TnUAD- 4/2014.

\section{References}

[1] Kováčiková, P., Vavro, J.,Vavro, J. Jn., Valášek, R., Identification of the fatigue characteristics of structural materials under cyclic loading. In: XVIII. Slovak - Polish International Scientific Conference. Machine Modeling and Simulations, Žilinská Univerzita v Žiline, 2013.

[2] STN 420 363: Skúšanie kovov, skúšky únavy kovov, metodika skúšania. Vydané 1. 10. 1986.

[3] Kováčiková, P., Vavro, J., Valášek, R., Vavro, J. ml.: Fatigue of Construction Steel under the Cycliv Loading = Únava konštrukčnej ocele pri cyklickom zat’ǎení, HUTNICKÉ LISTY, 2013, roč.LXVI, č. 7, s. 22-24.

[4] Hazlinger, M., Moravčík, R., Čaplovič, L', Degradačné procesy a predikcia životnosti materiálov, STU Bratislava, 2010.

[5] VAVRO, J.,HAJSKÁ, H., VAVRO, J ml.,VAVROVÁ, A.: Nové metódy a prístupy experimentálnej mechaniky pri identifikácii vád a porúch výrobkov. TnUAD 2011, 265 strán. 